\title{
Studies on the Internationalized Higher Education
}

\author{
Li-juan Ren \\ International College, Bohai University, Liaoning Province 121000, China \\ Tel: 86-416-3400215 E-mail: rlj6661@hotmail.com \\ Zheng Tang \\ Faculty of Engineering, University of Toyama, Toyama 3190, Japan \\ Tel: 81-76-4456752Ｅ-mail: tang@iis.toyama-u.ac.jp
}

\begin{abstract}
As for the heated problem of the Internationalized Higher Education (IHE), the thesis makes a deep research stating the tendency of IHE and focusing on the strategy and the issues that must be paid more attention to in the realization of the Internationalized Higher Education (IHE).

Keywords: The Internationalized Higher Education, The globalized economy, The international exchange

\section{Introduction}

The globalized economy and information cause the reform that the traditional education or methodology has never experienced for thousands of years. It is self evident that education, especially for IHE has become the fact, which is as well the heated topic currently in the field of the higher education. Actually, the process of the acceleration of IHE is not only the only way but the measures that the higher education must take when encountering the irresistible external challenges to improve the competition in the world.
\end{abstract}

\section{The connotation of IHE}

Educators understand IHE in quite different ways because of the broadening respects of it. Different scholars give the different definitions towards IHE; however, they have many things in common. Generally speaking, there are two definitions concerning with IHE: one is that IHE is understood with a result. The so-called IHE should be an advanced, opening and vigorous system, an ideal university education modal which people look forward to in order to keep pace with time. The other one is that it is understood as a tendency or a process as for the traditional or closed education system. It focuses on not only the degree of being internalized but also the process of its realization.

The so-called internationalized higher education refers to in the guidance of the international consciousness and the opening concept the higher education in a country or the certain concrete university is the dynamics and a developing tendency which promote the mutual understanding in the international societies, accelerate the international scholar position, participate the international education affairs, promotes the reform of IHE through international multi-exchange, multi- cooperation and multi-help. In a word, IHE refers to a process or a tendency that the universities in the respective country on the scale of global has to stand in the country inside and face to the outside world. It is a tendency of multi-exchange, multi-corporation and multi-help that is across the countries, across the nations and across cultures.

The aim of it, for the country, is to accelerate the education quality, go to the international stage and cultivate a group of talents who are strong in the global concept and the time sense and, who have the broadened vision and are able to adapt themselves to any situations with the creative spirits to adapt to the country's various needing of development. For the whole world its terminal purpose is to realize the exchange and melting in different cultures to improve the human being's progress and develop through the mutual absorbing of the advanced cultural fruits.

\section{The tendency of IHE}

We can say that the concept of IHE is time-honored, however, up till now a new state and new tendency have appeared towards the world economy. The new development gives the higher education deeper and wider connotation and a new mission will be attached to IHE. The tendency of IHE goes rapid. We can find the cause resulted in IHE by analyzing the historical development.

\subsection{The globalized economy}

The globalized economy refers to the accelerating the mutual existence among the various countries in the sense of 
living and marketing under the condition of the globalized information and the marketing. The globalized economy promotes the across country flowing in human resources, bonds, goods, service, knowledge, technology and information, accelerates the optimizing equipment in productive elements and the resources and promotes IHE. The globalized economy is the materialist foundation. The relationship between economy and education is mutual existing and mutual restraint. When the realization of the globalized economy comes true, it must influence the education deeply and cause the education resource to accelerate the international corporation and exchange more closely and more frequently in the world and force the education resources in different countries to open to the outside world simultaneously.

The globalized economy brings at the same time the brain needing and the globalized standard on talent. Some experts find that in the time of the globlaized economy the two-thirds trade are dealt in the internal transnational corporation or inter-transnational corporation. The enterprise must recruit the brain on the global scale and send them to the different countries in the world. This can bring the international talent flowing, and can as well lead to the international standard on brain. The manager and the employer who are engaged in the trade across the country have to not only gain the proficiency of the rules about the international operation in economy but also know more about local politics, economy and culture. This is the fundamental requirement towards the quality of the talents, which the enterprises operate across the countries in the tendency of the globalized economy. In the wanting of the market objectively the globalized economy accelerates the internationalized education. That's the tendency, which cannot be controlled by people's personal willing.

\subsection{The globalized information}

The globalized economy promotes at present the science and technology rapidly. The modern net of information, which the main body is computers, televisions, and satellites, has combined the world with one entirety forming tendency of the internationalized information. It breaks the division between the countries and regions, the people's traditional concepts and the division in cultures. It provides the internationalized higher education with the necessary conditions. The convenient Internet converses the various universities in the world into a global scholar community, which causes a more and more closed relationship among the universities respectively. It makes easier in the exchange in academy, the mutual utility of curriculum and mutual understanding in concept, especially that the technology of computerizing Internet causes the reform in the higher education, i.e., the higher education is able to work facing with the whole world and eventually it can use for reference from the advantage of the modern net education.

\subsection{Internality of the higher education}

The education is generally regarded as a production in the world. Hence, the market in education is fiercely competitive. In particular, in the Western developed countries, the prestigious universities stand like a forest; the student resources are fiercely competitive. Because of the limited students resources and the declining of the government budget the higher education is eager to widen the education market abroad. Furthermore, the whole national economy and the other advantages makes easier to open the market in the developing countries. This phenomenon accelerates the internationalized higher education. Simulneneously the developed countries take the dominant position and play the leading role in the exchange of the international education. Having the aid of IHE the developed countries can strengthen the cultural permeating to the developing countries. In addition, in the international exchange of education the developed country can not only appeal many batches of the first-rate brain in the developing countries in a low price but also gain the tremendous profit in economy. In particular, the reform taken in the developing and undeveloped countries need guiding in education concepts, the modal in management in education and the education experience from the developed countries to make the native education vigorous. This as well needs international exchanging and cooperating, i.e., not only to improve the local education and gain some advanced technology and experience but also is useful in broaden the local people's vision and promote the opening to the outside world, make social progress and accelerate the process of the moderation of the society.

\subsection{Globalized issues}

Opening our eyes to the whole world we find that human being are facing with the globalized issues such as accelerating the difference between the poor and the rich, the regional wars, the degeneration of the environment, the population expansion and the resources exhaustion. It is difficult for any agency or a certain country to solve these serious problems. It needs the whole world's participation and cooperation. The education is not only the tool to win the victory in the global competition but also the historical responsibility that we human being take to make the earth develop better and more beautiful. Just according to a report pointed out from UNESCO Learning-the Wealth Concealing in It that "education has to take the special responsibility for building a more united world, however, as for the future various challenges that we have encounter, education seemingly is a necessary trump card which causes human being march on the road of peace, justice and freedom."

\section{The measures of realizing IHE}

IHE is a developing tendency including various concrete activities. The purpose of it lies in providing a kind of 
education experience, which can melt in the global sense. It includes three respects: firstly, it concerns with the international content in the curriculum; secondly it is the content concerning with the research and training in international exchange in scholar and students; finally it is the international technological favor and the scheme in the international cooperation.

\subsection{Concept of IHE and goal}

Comrade Deng Xiaoping said early in 1983 that education should be facing to the modernization, facing to the whole world and facing to the future. In fact, this needs to take an internationalized road. The prerequisite of accelerating the process of the internationalized higher education is to break the old thoughts and the traditional ideas. Some educators worry about that the internationalized higher education will pound at the local education and the local culture. This pounding will take the side effect. Although these worries are in some sense rational we couldn't see the negative side only, whereas, we'd better see the positive side. We have to see that IHE is the tendency in the social development, which cannot be centered on the people's willing and cannot be hindered by people. We must welcome it, adapt to it and make the full use of it minimizing the negative affect simultaneously. However the first task of making the education concept internationalized is to establish the training goal of the international brains which conforms to IHE and cultivate the brains who have the global vision, keep pace with time and competitive in the international stage. The quality of being an international person includes first, the international attitude including concerning with the earth, human being; adapting to the changes creating future; fair competition and friendly cooperation; self-respect with self-confidence; taking efforts to improve oneself; second, The international concept including the sense of international understanding, mutual-existence, the peaceful development and the international justice; third, the capability of international communication including the independent ability in thinking, the competence of participation, the ability of dealing with the information, the ability in life long learning, the ability of enduring the frustration and the competence of the international communication; fourth, the international knowledge including knowing the international current affairs, the history and tendency of the world development, the essence of oriental and Western cultures, the nation's central position and the role in the world; shouldering the mission of building the motherland and having the consciousness of serving the whole human being; finally, to gain the proficiency of at least one kind of foreign language.

\subsection{Internationalized curriculum}

In order to build the international education market we must provide the higher education with scientific and rational content of teaching and learning which should follow the international principles, for the cultivation of the brain is realized though the process of education. In other words, the quality of the education should experience the course structure and the teaching and learning. When the Western countries participate the internationalized higher education they take the reform in the course structure and the content of teaching and learning. In the United States in 1970s,in the curriculum of Bachelor education, the new courses of the Western Culture, the International Relations, The International Economy, The International Trade and the Studies on Third Worlds are compulsory. The Australian Curriculum Organization in the seventh plenary of the National Conference points out a new course concept_- the globalized curriculum saying that it is not a concrete course but a new concept towards the education and course focusing on the globalized consciousness in curriculum. In order to adapt to the internationalized higher education in the systematic education and the curriculum the universities have to take the reform. The measures are as follow: first, offer the international courses such as The International Politics, The International Economy, The International Trades, The Foreign History, Geography, The Costumes, etc.. second, add some knowledge in foreign advanced science and culture with their scientific and technological fruits; finally, select the most advanced text books in the world and appeal foreign experts and the scholars to be the visiting scholar.

\subsection{The market of study abroad}

The globalized economy is forming the international tendency in the higher education rapidly. Expanding the international market in study abroad has been the common strategy in the Western countries and America. The total amount of the students of study abroad is over 1 million. Among them half of it is in the United States. The average consumption annually is \$ 20 thousand, for they eat, stay and take the transport in America. This only can provide the United States with 10 billion bonds annually. The United States is a country which appeals to the most amount of students of study abroad and gets rewards most in return. Britain now is advocating building a superpower of students study abroad. Britain has been sponsoring the displays of education in the foreign countries to appeal most foreign students. Japan, the developed country is taking actively the measures to appeal to the foreign students This measure not only bring them with a lot of profit, but also cultivate a batch of first-rate brains who are the cheap "employers" "the part-time workers". These measures contribute more to the acceleration of the economy, science and technology in Japan. The developed countries today, evaluate the universities with the degree of the internationalized higher education of the students and faculties in the universities. They regard building the university across the country, developing the tele-education and promoting the international cooperation in scientific research and teaching and learning as their main tasks. 


\subsection{The international exchange}

IHE refers to making full use of the international education resources and making the native education resources open fully to the outside world to improve the education and the economy. The measures are as follow:

\subsubsection{Strengthening the international exchange with teachers}

It is an important road for the higher education to strengthen and to expand the international exchange with teachers and to export and import the resources actively. Exchanging is the root of the creation in academy. The academic life will be suffocated to death without the exchange, mutual complementing, striking and melting. As for the exchange in visiting scholars and visiting teachers, one way is to send them out, that is to send the skillful and noble scholars and teachers to the first-rate universities or scientific institutes to engage in the research in the advanced science and the fundamental science. In this way they are able to not only get and absorb a lot of latest knowledge, improve their foreign languages and improve their capability of handling but also learn a great deal of latest educative concept and methodology. Another way is to invite, that is to invite the famous scholar and the experts in the world to the local universities to teach and become the visiting scholar and to have the seminar or to cooperate with the academic institutes to have the further researches, to have the academic discussion. This is useful not only to avoid the popularizing of the out of moded and irrational structure in knowledge but also to weed through the old to bring forth the new by way of adopting good advice from all quarters and achieving mastery through a comprehensive study. In this way it can make the new increasing pointing in the academic studies forming the good recycle in the higher education with scientific research and make the advantages mutual-complement.

\subsubsection{Strengthening the multi-cooperation in academic research}

Since science and technology develops rapidly the respective country have its own advantages with its disadvantages so long as the universities strengthen the exchange and carve and polish each other they can learn from each other to make up progress and contribute to the education and scientific development. According to the developing tendency and through observing the situations at the present the multi-cooperation among the universities includes mainly the universities in different countries have to open each other, make interuniversity exchange in academy, issue the thesis in the prestigious academic periodicals abroad, make the financial help to invite the colleagues abroad to participate the local research of the big-sized science and technology item, the designing across the countries and sponsor the relevant scientific research subject to pursue together. Build the information net according to the subject and major making the mutual-complement and mutual-help in the international education resources. Strengthen the cooperation between the researchers research institutes and the corporation cross the countries. Sponsor the international seminars.

\subsubsection{Accelerating the international setting up education in cooperation}

With the development of the international exchange and cooperation in higher education the international cooperative setting up education a new force of international cooperative setting up education in higher education suddenly comes to the fore, and it develops rapidly. In1980s, a great upsurge in setting up education across countries was taken in the Western and American countries. There fore mainly four sorts of international cooperative setting up education: first, the developing countries are actively looking for opportunities of cooperative setting up higher education with developed countries. Second, developed countries want to cooperate with developed countries in higher education. Third, developed countries cooperate with developing countries in setting higher education. Finally, Local universities establish the brotherhood with universities, the academic institutes in foreign countries sending students and teachers to the target cooperative universities to have further study and research.

\section{The problems in accelerating IHE}

IHE is slow in development. It is not advisable for any educators to be prompted by sudden impulse in setting up IHE. However, it is also not advisable for us to wait passively. It will bring the tremendous damage to the career of the higher education. We must promote IHE with an active attitude. So there are four issues that we have to pay attention to:

\subsection{Paying much attention to the humanities education}

To be national is to be international. IHE should embody the utility that the native education absorbs from foreign educations, the locality, and the nationality that the local education forms, becoming the export country in higher education again and finally the cultural exchange become mutual. The Principal of French Normal University Aolu takes the view that the loss in multi-cultures will bring about the affects to the development of human knowledge. If cultures are assimilated, it will fail to develop further.

\subsection{Keeping its own characteristics without imitation in reform of higher education}

We have to avoid losing the original advantages which adopts to our education when accelerating the process of IHE and keep off the draw backs of the traditional education. The locality and nationality of higher education cannot take the place of IHE, or cannot make the excuses of the systems lag behind and denying the advanced culture. Internationality cannot deny the nationality, but should strengthen the characteristics of nationality and promote it to the international 
degree in characteristics forming a tendency of going forward one by one. The two parties should be co-existed and contradictory. So long as higher education takes the road combined the nationality with the internationality higher education is able to occupy a pivotal position in IHE. The authentic IHE is to keep the national characteristics and curry out according to the international rules but not the colonial education.

\section{References}

Liu, Hai-feng. (2001). The Localization and Internalization of Higher Education. P.21.

The Internationalized Higher Education Is a Tendency, Wenhui News Paper.

The UNESCO Organization learns to survive_-Today, Tomorrow of the Educational World, Education and Science Publish House.

The history of Higher education in America, Fujian Education Publishing House.

Tony Spybey. (1996). Globalization and World Society, Polity Press in association with Blackwell Publishers Ltd, P.102.

Yang, Dong-ping. (2000). University Spirit. Liaohai Publishing House. P. 123. 